\title{
Axonal Transport and Distribution of Synaptobrevin I and II in the Rat Peripheral Nervous System
}

\author{
Jia-Yi Li, ${ }^{1}$ Lambert Edelmann, ${ }^{2}$ Reinhard Jahn, ${ }^{2}$ and Annica Dahlström ${ }^{1}$ \\ ${ }^{1}$ Department of Anatomy and Cell Biology, University of Göteborg, S-413 90 Göteborg, Sweden, and ${ }^{2 H o w a r d ~ H u g h e s ~}$ \\ Medical Institute and Departments of Pharmacology and Cell Biology, Yale University School of Medicine, New Haven, \\ Connecticut 06536
}

Synaptobrevin, a membrane protein of synaptic vesicles that plays a key role in exocytosis, occurs in two closely related isoforms, synaptobrevin I and II. We have analyzed the axonal transport of both isoforms in sciatic nerve and spinal roots. When fast axonal transport was interrupted by crushing, the proteins accumulated continuously proximal to the crush. Accumulation also was observed distal to the crush, but to a lesser extent (47 and $63 \%$ of the proximal accumulation for synaptobrevin I and II, respectively). Immunoelectron microscopy revealed that, proximal to the crush, synaptobrevin I and II were associated with small clear vesicles reminiscent of typical synaptic vesicles. Distal to the crush, membranes positive for synaptobrevin I or II were more heterogeneous, including larger membrane profiles that may represent endosomes. In spinal cord, synaptobrevin I and II were colocalized in many terminals. However, labeling for synaptobrevin I was more intense in ventral horn nerve terminals than in dorsal horn terminals, whereas labeling for synaptobrevin II was stronger in dorsal than in ventral horn terminals. Motor endplates contained only synaptobrevin I. In the sciatic nerve, synaptobrevin I was present predominantly in large, myelinated axons, whereas synaptobrevin II was virtually absent, but abundant in small- and medium-sized axons. Lumbar sympathectomy, ventral rhizotomy, and double-labeling studies confirmed that synaptobrevin $\mathrm{I}$ is present predominantly in motor neurons, whereas synaptobrevin II is present in adrenergic and sensory neurons.

We conclude that synaptobrevin I and II are transported bidirectionally by fast axonal transport and are expressed heterogeneously in different neurons in the peripheral nervous system of the adult rat, suggesting that these isoforms have special functional roles in different sets of neurons.

Key words: synaptobrevins; axonal transport; synaptic vesicles; motor neurons; sympathetic adrenergic neuron; sensory neuron; immunofluorescence; confocal laser scanning microscopy
Communication between neurons occurs at specialized contact areas known as the synapses and is mediated by neurotransmitters that are released by exocytosis of synaptic vesicles. The vesicle membrane is then retrieved by endocytosis and regenerated, probably involving passage through clathrin-coated vesicles and endosomal intermediate compartments (for review, see Jahn and Südhof, 1994; Bennett and Scheller, 1994).

Recently, major progress has been made in our understanding of the molecular mechanisms that underlie exocytotic membrane fusion. Exocytosis is mediated by a set of conserved membrane proteins that interact with soluble factors, termed $N$-ethylmaleimide-sensitive factors (NSF), and with soluble NSF attachment proteins (SNAPs). The membrane proteins are synaptobrevin (also referred to as vesicle-associated membrane protein) and the synaptic membrane proteins syntaxin and SNAP-25. Recent evidence suggests that most, and possibly all, intracellular fusion

Received April 25, 1995; revised Sept. 20, 1995; accepted Sept. 27, 1995.

This work was supported by the Swedish Medical Research Council (Grant 2207), the Royal Academy of Science and Arts in Göteborg, Gustav V:s 80-årsfond, Stiflelsen Lars Hiertas Minne, and by the Swedish Society for Medical Research. Support was given to R.J. by a United States Public Health Service grant (Program Project PO1 Ca 46128). We are grateful to Dr. Menek Goldstein (New York University) for a generous supply of antibody for tyrosine hydroxylase, Dr. Pietro De Camilli (Howard Hughes Medical Institute, Yale University) for helpful discussions and critical advice.

Correspondence should be addressed to $\mathrm{Dr}$. Jia-Yi Li, Department of Anatomy and Cell Biology, University of Göteborg, Medicinaregatan 5, S-413 90 Göteborg, Sweden.

Copyright (C) 1995 Society for Neuroscience 0270-6474/95/160137-11\$05.00/0 events in eukaryotic cells are mediated by relatives of these membrane proteins (for review, see Rothman and Warren, 1994; Ferro-Novick and Jahn, 1994).

Synaptobrevin is an integral membrane protein of $\sim 18,000 \mathrm{Da}$ anchored to the vesicle membrane by means of a single transmembrane domain at the C-terminal end of the molecule, and highly conserved during evolution (Südhof et al., 1989a). Synaptobrevin is selectively cleaved by clostridial neurotoxins that potently inhibit exocytosis (Link et al., 1992; Schiavo et al., 1992; Yamasaki et al., 1994a-c), thus demonstrating that the protein is essential for exocytotic membrane fusion. Although the mechanism of action of synaptobrevin remains to be established, it is likely that it mediates its activity by specific protein-protein interactions (Calakos et al., 1994; Pevsner et al., 1994). Recent data suggest that it forms a stable prefusion complex with the membrane proteins SNAP-25 and syntaxin 1 after vesicle docking, whereas in the resting state it is controlled by synaptophysin, a major membrane protein of synaptic vesicles (Calakos and Scheller, 1994; Damer and Creutz, 1994; Edelmann et al., 1995).

In the mammalian nervous system, two isoforms of synaptobrevin (synaptobrevin I and II) have been detected. They are highly homologous to each other but are encoded by two separate genes (Elferink et al., 1989). Such isoform variety is common for synaptic vesicle membrane proteins (for revicw, sec Jahn and Südhof, 1994), but its functional significance is unknown. In addition, a highly homologous protein, cellubrevin, has recently been characterized. In contrast to synaptobrevin I and II, cellubrevin is 


\section{Synaptobrevin I}

A

\section{Synaptobrevin II}

Oh
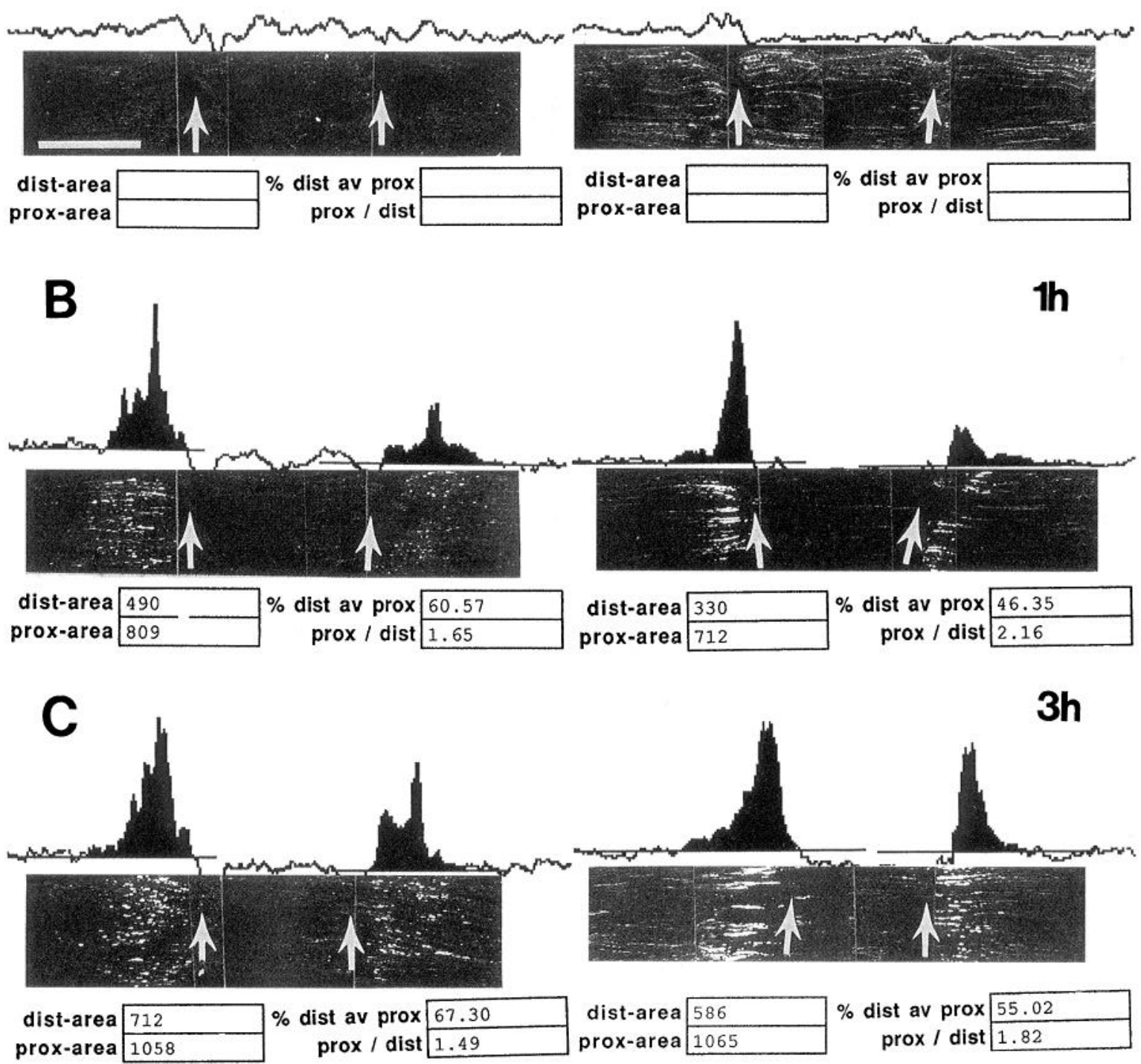

$\%$ dist av prox 67.30 prox / dist 1.49

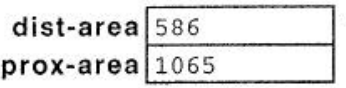

$\%$ dist av prox 55.02

prox / dist 1.82

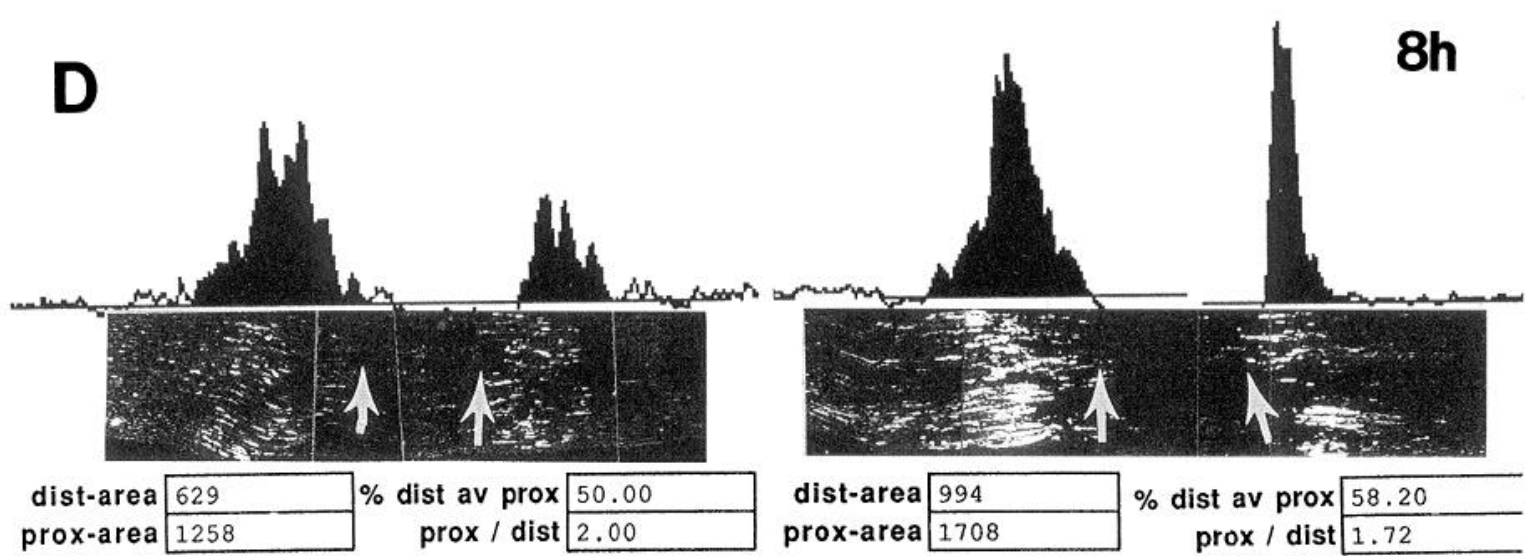



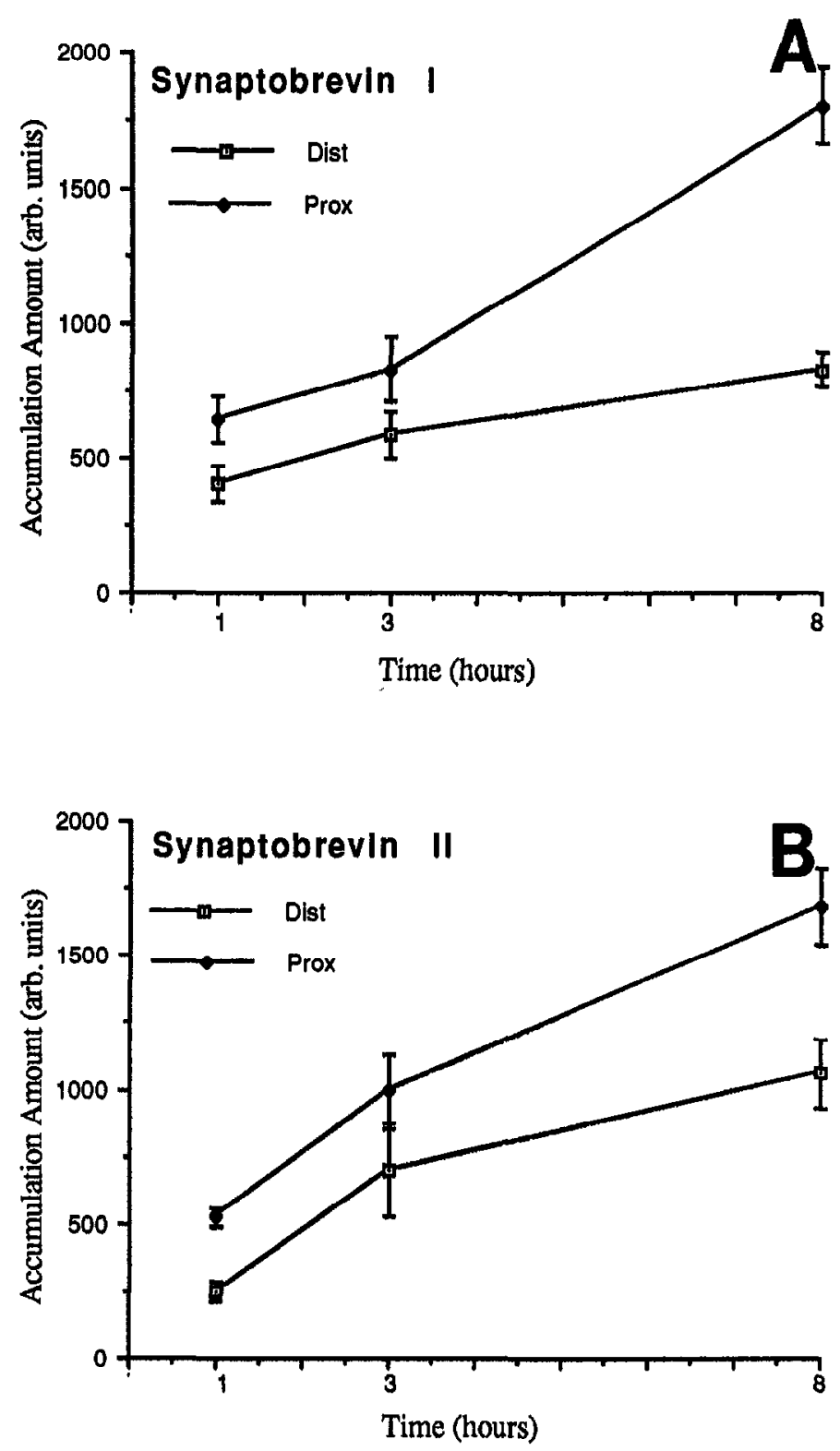

Figure 2. Time course of accumulation of synaptobrevin I $(A)$ and II $(B)$ based on CFS data. Each time point consists of four rats, and mean \pm SEM are shown. Prox and Dist represent the proximal and distal accumulation. Four to six sections from each nerve were incubated with antisynaptobrevin I and II, respectively. The means from these sections in each individual nerve were used to calculate the final means.

expressed predominantly in non-neuronal cells and is required for constitutive exocytosis. Like the other synaptic vesicle proteins (Südhof et al., 1989b; Geppert et al., 1991; Baldini et al., 1992; Fykse et al., 1993), synaptobrevin I and II are differentially expressed in the brain. Using in situ hybridization, Trimble et al. (1990) found that synaptobrevin I was expressed in some CNS nuclei, modulating somatomotor functions, whereas synaptobre- vin II, the predominant isoform in the CNS, was expressed preferably in nuclei associated with autonomic, sensory, and integrative functions. However, a study addressing the detailed distribution of synaptobrevin I and II proteins has not yet been carried out.

In the present study, we have investigated the distribution of synaptobrevin I and II in the peripheral nervous system. Our results show that both proteins are transported by fast anterograde and retrograde axonal transport but that they are expressed differentially in different neurons.

\section{MATERIALS AND METHODS}

Adult male Sprague-Dawley rats $(200-250 \mathrm{gm})$ were used. Under ether anesthesia, the sciatic nerves were exposed bilaterally and double-crushed as described earlier (Dahlström et al., 1989). To study accumulations of vesicle components in the motor or sensory neurons, the ventral and dorsal roots were crush-operated using watchmakers' forceps. The operation was performed via a dorsal approach as described in detail by Bööj et al. (1989).

To investigate the differential distribution of synaptobrevins in autonomic sympathetic, motor, and sensory systems, the following operations werc performed with the purposc of studying the ncuronal origin. (1) Lumbar sympathectomy was performed by removing the lumbar sympathetic chain bilaterally (Dahlström et al., 1985). This procedure removed $>95 \%$ of the postganglionic axons in the sciatic nerve, leaving sensory and somatic motor fibers intact. (2) Motor rhizotomy was achieved by cutting the ventral roots L2-L6 (the roots that form the sciatic nerve). The sympathectomized or rhizotomized rats were allowed to survive for 3 or $8 \mathrm{~d}$. Six hours before sacrifice, the sciatic nerves of the rats were double-crushed as described above. All procedures and handling of the rats were performed in accordance with the rules of the Animal Ethical Committee in Göteborg.

After transcardial perfusion fixation with $4 \% p$-formaldehyde, $\mathrm{pH} 7.4$, under deep mebumal anesthesia, the sciatic nerves, the spinal roots, the gastrocnemic and peroneal muscles, the L3-L6 dorsal root ganglia (DRG), and the lumbar spinal cord were dissected and postfixed in the same fixative for $3 \mathrm{hr}$. The samples were then rinsed overnight in PBS with $10 \%$ sucrose, frozen with compressed $\mathrm{CO}_{2}$, sectioned at $10 \mu \mathrm{m}$ longitudinally (nerves, roots, DRG, and muscles) or transversely (spinal cord) in a cryostat, and placed on gelatinized glass slides. Indirect immunofluorescence incubations were performed using the following primary antibodies:

(1) Anti-synaptobrevin $I$, rabbit antiserum produced against the $\mathrm{N}$ terminal of synaptobrevin I (Edelmann et al., 1995), dilution 1:800;

(2) Anti-synaptobrevin II (Cl 69.1), mouse monoclonal antibody against the $\mathrm{N}$-terminal of synaptobrevin II (Edelmann et al., 1995), dilution $1: 800$;

(3) Anti-tyrosine hydroxylase (TH), rabbit antiserum raised against TH isolated from human pheochromocytomas (Goldstein et al, 1972), (donated by Dr. M. Goldstein), dilution 1:800;

(4) Anti-substance $P(S P$; RPN 1572), produced in rabbits against synthetic SP, (Amersham, Buckinghamshire, UK), dilution 1:400.

Single- and double-immunofluorescence incubations of tissue sections were performed as described ( $\mathrm{Li}$ et al., 1992, 1994).

In the sections labeled separately for synaptobrevin I or II, the immunoreactive material accumulating proximally and distally to the crushes was quantitated by cytofluorimetric scanning (CSF) as described in detail earlier (Larsson, 1985; Dahlström et al., 1989). To allow for comparison between different sections, all sections of one series were processed strictly in parallel, using the same solutions for the primary and secondary antibodies. Furthermore, identical scanning sensitivities were used for all sections compared. The reliability of this method was established previously by comparing CSF data with those obtained by enzymatic methods (Larsson, 1985; Dahılström el al., 1989).

\section{$\leftarrow$}

Figure 1. CSF graphs with the corresponding photomicrographs of sciatic nerve sections after incubation with anti-synaptobrevin I (left lane) and anti-synaptobrevin II (right lane), $0(A), 1(B), 3(C)$, or $8 \mathrm{hr}(D)$ after crush operation. The arrows indicate the sites of crushes. The proximal orientation is to the left. The sensitivity of CFS and confocal settings (voltage, pinhole, and gain level, etc.) were set in the same level while collecting the data between different time points. Distinct accumulations of immunoreactive materials can be observed $1 \mathrm{hr}$ after crushing, and the amounts of accumulations increased thereafter. The right upper frames below the photomicrographs show the percentage between the distal and proximal accumulations. Scale bar, $1 \mathrm{~mm}$. 


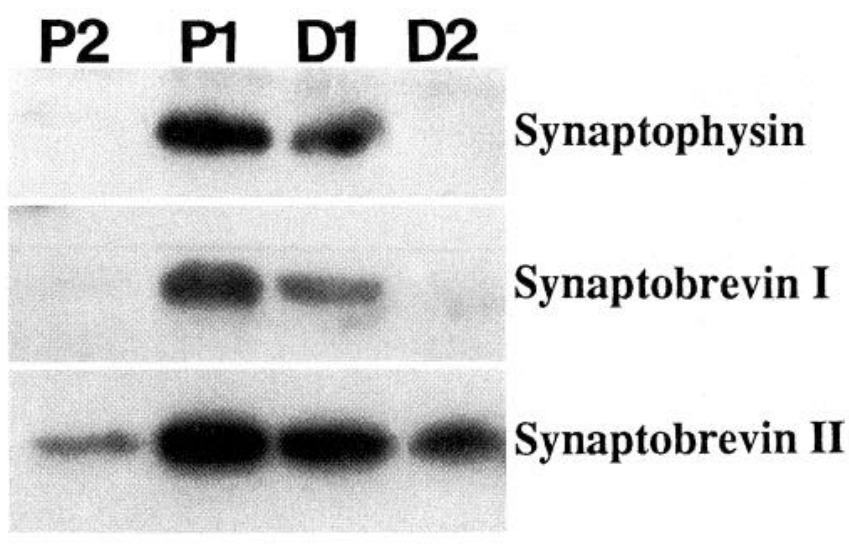

Figure 3. Immunoblot of sciatic nerve fragments $6 \mathrm{hr}$ after crush operation. $P 1$ and $D 1$ represent the proximal and distal fragments (1 mm long) close to the crush; $P 2$ and $D 2$ represent the proximal and distal fragments $10-15 \mathrm{~mm}$ away from the crush. The immunoreactivities of synaptobrevin I and II as well as synaptophysin are more intense in P1 and D1 than that in P2 and D2, representing the accumulations that have developed after operation. However, clear bands also can be seen in P2 and D2 (synaptobrevin II), indicating the presence of certain fractions of synaptobrevin II in normal, unlesioned sciatic nerve.

Single- and double-labeled samples were then studied in a confocal laser scanning microscope (CLSM) with a krypton/argon lasser (MRC 600, Bio-Rad Laboratories, Richmond, CA), using single- or dual-channel scanning. Colocalization was verified by merging the two channels in two colors and also switching between the channels. In dual-channel scanning, the confocal parameters, such as voltage, offset, gain level, pinhole, and the background level, were set to similar levels for collecting the images in each double-labeled sample. Photographs were taken using Kodak TX 400 film.

Electron microscopy. The procedures basically followed those described by De Camilli et al. (1983). Briefly, $6 \mathrm{hr}$ after crush operation, the sciatic nerves were immediately dissected and cut into proximal and distal segments adjacent to the crushes, and then were gently homogenized with small glass-glass grinders. After fixation, the fragments were centrifugated at $16,500 \mathrm{rpm}$ for $45 \mathrm{~min}$, and the pellet was embedded into $1 \%$ agarose. Immunogold labeling was performed using Protein A gold (De Camilli et al., 1983).

Immunoblot experiments. Six hours after operation, the fresh nerve fragments (1 mm long), from proximal and distal areas close to or 10-15 $\mathrm{mm}$ away from the crushes were immediately frozen in liquid nitrogen (cf. Li et al., 1995). Fragments from five rats were pooled and homogenized in glass-glass homogenizers in sample buffer (containing $1 \%$ SDS, $10 \mathrm{~mm}$ Tris, $50 \mathrm{~mm} \mathrm{NaCl}$, and pepstatin A). SDS-PAGE ( $5 \mathrm{mg} / \mathrm{lane})$ was performed according to Laemmli (1970). Immunoblotting was performed according to Towbin et al. (1979), using radioiodinated Protein A as the detection system. Protein content was determined by the method of Bradford (1976). When tested by immunoblotting, all synaptobrevin Iand II-specific antibodies reacted only with a single band

\section{RESULTS}

\section{Synaptobrevin I and II are transported by fast axonal transport}

To investigate how the synaptobrevins are transported between neuronal cell bodies and distally located synaptic areas, we performed crush operation on sciatic nerves and spinal roots. This technique previously has been shown to block axonal transport while anterogradely and retrogradely transported material accumulates on the proximal and distal side of the crush, respectively (Dahlström et al., 1989; Dahlström and Li, 1994). As shown in Figure 1, a short time (1 hr) after crush operation accumulations of immunoreactive synaptobrevin I and II were observed on both sides of the crushes (Fig. $1 B$ ). The accumulations were not caused by the crushing procedure per se, because accumulations were not
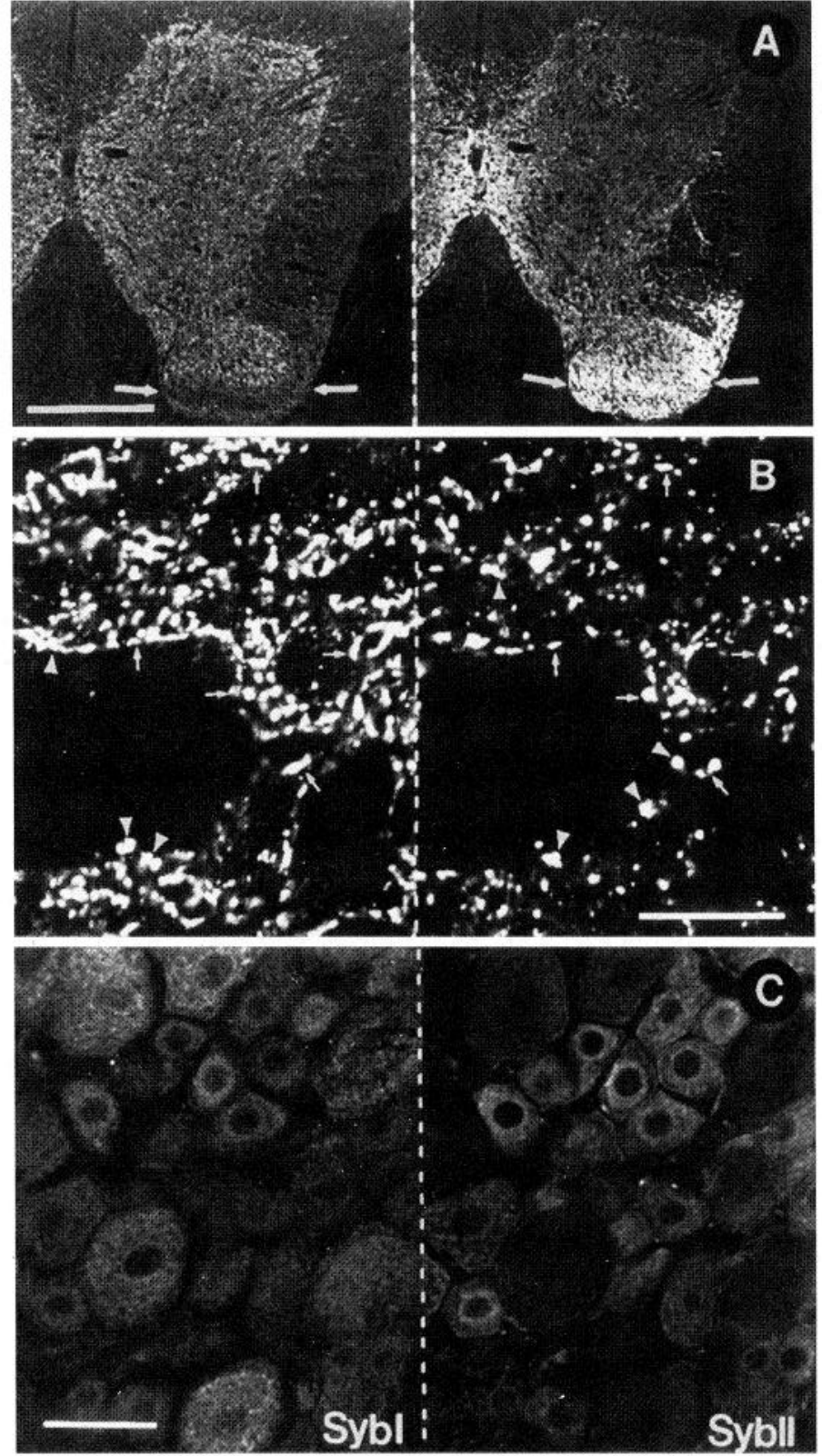

Figure 4. CLSM photomicrographs of spinal cord ( $A$ and $B)$ and DRG (C). The sections were double-incubated with anti-synaptobrevin I (left lane) and anti-synaptobrevin II (right lane). The dotted lines mark the border between the two channels. $A$, Synaptobrevin I-IR is abundant and intensely present in terminals in the ventral horn of the spinal cord, but sparse and weakly fluorescent in the dorsal horn, especially in laminae I an II (arrows). In contrast, synaptobrevin II-positive terminals are abundant in a dense network in the dorsal horn, e.g., laminae I-III, and the region around the central canal (lamina X), but less abundant and weaker in fluorescence intensity in the ventral horn. $B$, The two proteins are partly colocalized in the terminals of spinal cord (arrows), but terminals positive for either synaptobrevin I or II also can be seen (arrowheads). C, Synaptobrevin I-IR is localized in large DRG neurons, which are devoid of synaptobrevin II-IR. However, synaptobrevin I and II appear colocalized in small- and medium-sized neurons. Scale bars: $250 \mu \mathrm{m}$ in $A ; 25 \mu \mathrm{m}$ in $B$ and $C$.

registered in nerves that were crushed just before perfusion (Fig. 1A). Thus, the accumulations had developed during the $1 \mathrm{hr}$ interval between operation and perfusion as a result of fast axonal transport. Clear accumulation of synaptobrevin II appeared after 

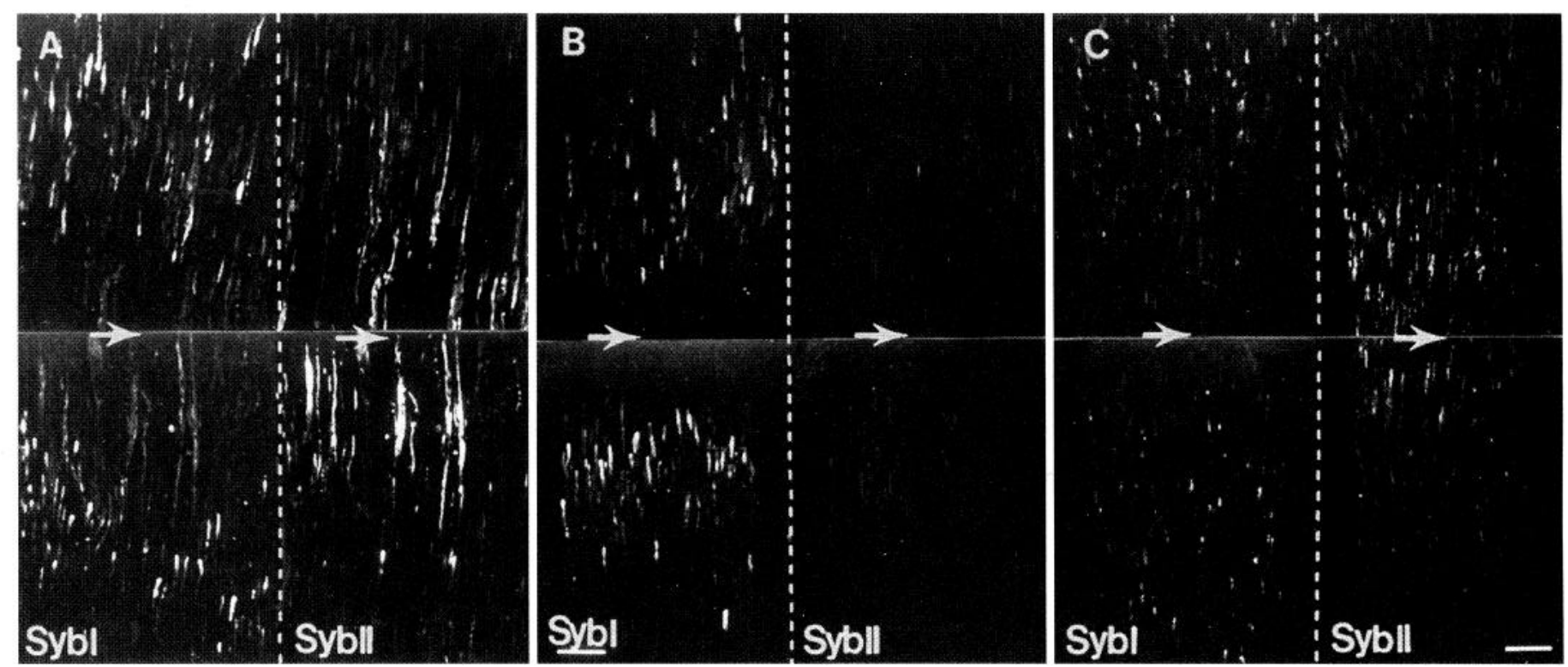

Figure 5. CLSM photomicrographs of sciatic nerve $(A)$, ventral root $(B)$, and dorsal root $(C) 6 \mathrm{hr}$ after crush operation. The sections are double-labeled with anti-synaptobrevin I (left lane) and anti-synaptobrevin II (right lane). The dotted lines mark the border between the two channels. Arrows indicate the sites of the crush, and proximal orientation is to the top. $A$, Synaptobrevin I-IR is intensely in the large axons proximal and distal to the crush of the sciatic nerve, whereas synaptobrevin II-IR is localized in bundles of small- and medium-sized axons. $B$, Synaptobrevin I-IR is strongly present in the axons proximal and distal to the crush of ventral root. However, only traces of synaptobrevin II-IR can be seen in the axons that are strongly positive for synaptobrevin I. C, Synaptobrevin I-IR is present mainly in.large axons and some medium-sized axons in dorsal roots, whereas synaptobrevin II-IR is present in thin and medium-sized axons. Scale bars, $100 \mu \mathrm{m}$.

crushing, but some synaptobrevin II-positive axons also could be observed in the regions far away from the crushes as well as in the $0 \mathrm{hr}$ crushed nerve sections (Fig. 1A), indicating that moderate amounts of synaptobrevin II are present in the intact sciatic nerve (also see Fig. 3). In animals perfused at later intervals after operation, the amount of accumulated immunoreactivity (IR) increased linearly with time (Figs. 1,2) on both sides of the crush. However, the amount of IR accumulating distally was consistently less than that accumulating proximally (47 and $63 \%$ for synaptobrevin I and II, respectively, as quantitated by CSF). This indicates that, similar to other vesicle membrane proteins (Bööj et al., 1986; Li et al., 1992), the synaptobrevins are degraded partially in the nerve terminals and in the distal zone of the axon.

To confirm the identity of the accumulated immunoreactive material, an immunoblot analysis was performed. Six hours after crush operation, the sciatic nerve was prepared and cut into four small segments of $1 \mathrm{~mm}$ each, two proximal (P2 and P1) and two distal (D1 and D2) of the crush [see Fig. 1 in Li et al. (1995)]. In the fragments directly adjacent to the crushes (P1 and D1), high levels of both synaptobrevins were detectable (Fig. 3). In contrast, the fragments that were sampled $10-15 \mathrm{~mm}$ away from the crushes (P2 and D2) contained significantly lower amounts of both proteins. These data demonstrate that the accumulated immunoreactive material corresponds to synaptobrevin I and II proteins. However, it can be noted that the amount of synaptobrevin II-IR is higher in D2 than in P2 for reasons that are still unclear.

\section{Synaptobrevin I and II are differentially distributed in the peripheral nervous system}

Although both synaptobrevin I and II were demonstrated to be transported by fast axonal transport, the distribution of the two isoforms differed. In the spinal cord, synaptobrevin I immunoreactivity was more intense in the terminals of the ventral horn than of the dorsol horn, whereas synaptobrevin II-IR was more intense in the dorsal horn (laminae I-III) (Fig. 4A). Both synaptobrevin I-IR and II-IR appeared to be absent from the perikarya of the motor neurons, which is in agreement with the absence of synaptobrevin from perikarya of motoneurons in brainstem (Baumert et al., 1989). In many cases, synaptobrevin I and II were colocalized in the same terminals (Fig. $4 B$, arrows), but we also observed terminals that contained either synaptobrevin I or II (Fig. $4 B$, arrowheads).

In the DRG, synaptobrevin I and II were distributed differentially in different sets of neurons. Synaptobrevin I-IR was strong in the large neuronal cell bodies, in which synaptobrevin II-IR was very weak. However, both proteins were present in some smalland medium-sized neurons, although synaptobrevin II-IR was more intense than synaptobrevin I-IR (Fig. 4C).

These differences in distribution prompted us to compare the localization of both synaptobrevins in the sciatic nerve and in the dorsal and ventral roots at higher resolution. In the sciatic nerve, synaptobrevin I-IR accumulated predominantly in large axons (probably motor axons) at a distance from the crush (Fig. 5A). Weak immunoreactivity also was found in thin and medium-sized axons. Synaptobrevin II-IR, in contrast, was present mainly in thin and medium-sized axons, which are grouped in bundles and always present their accumulations near the crush (Li et al., 1992, 1994). In these axons there was only partial overlap with synaptobrevin I-IR (Fig. 5A). Moreover, synaptobrevin I-IR accumulated in the axons of ventral roots after crushing, whereas synaptobrevin II-IR was observed only as weakly fluorescent traces on both sides of the crushes (Fig. 5B). In dorsal roots, synaptobrevin I accumulations were present in large axons, whereas synaptobrevin II-IR accumulated in small- and medium-sized axons (Fig. 5C) which presumably originate from the small neurons in the DRG. Studies in high magnification $(100 \times$, NA 1.4) confirmed that 

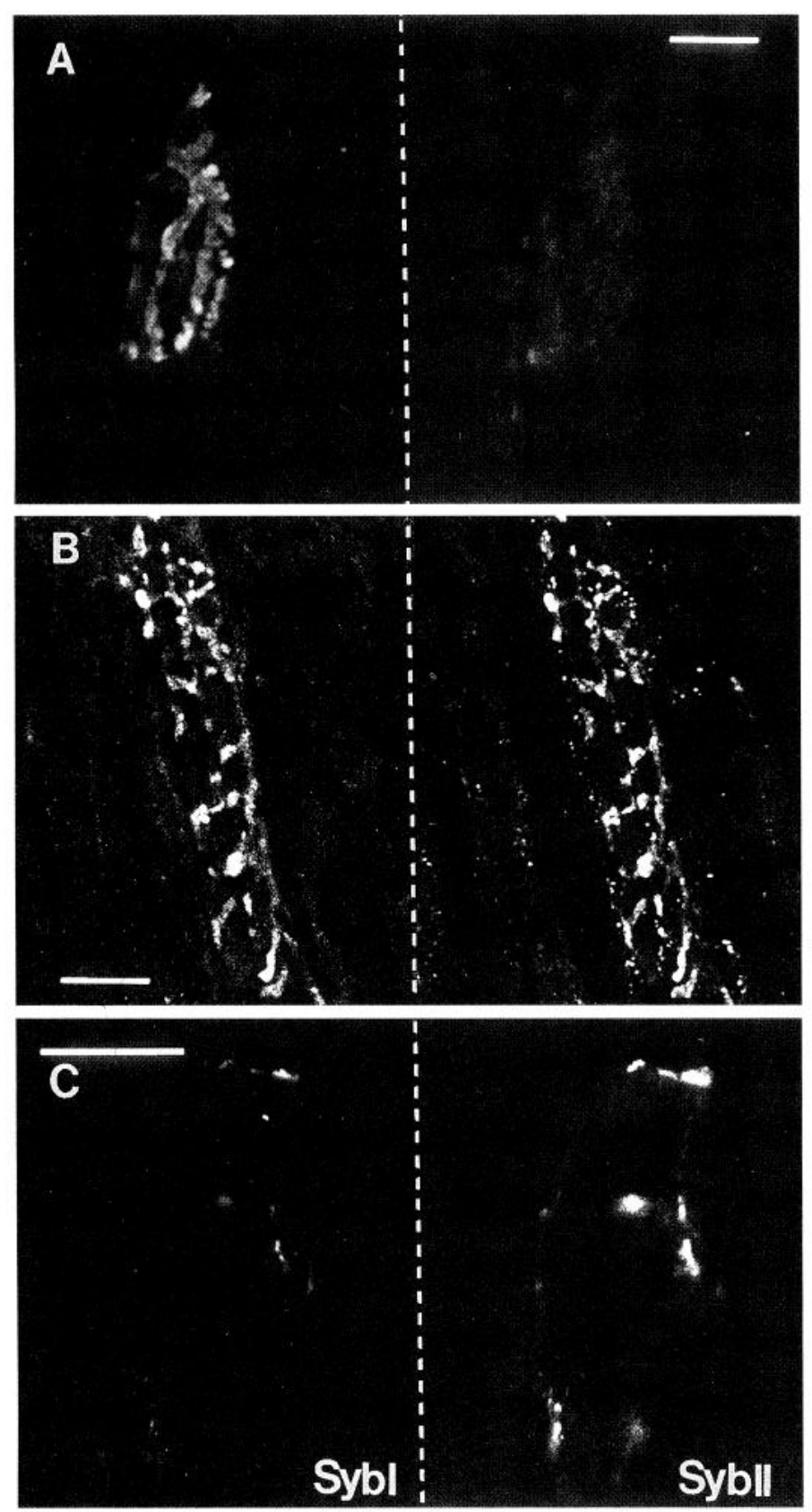

Figure 6. CLSM photomicrographs of motor endplate $(A)$, muscle spindle $(B)$, and perivascular terminals $(C)$. The sections were double-incubated with anti-synaptobrevin I (left lane) and anti-synaptobrevin II (right lane). The dotted lines indicate the border between the two channels. Synaptobrevin I-IR is abundant in motor endplates $(A)$, where no or very low levels of synaptobrevin II-IR can be detected. $B$, In muscle spindles, synaptobrevin I-IR and II-IR are colocalized. $C$, Synaptobrevin I-IR is sparsely present in some perivascular terminals, whereas synaptobrevin II-IR is very intense. Scale bars, $25 \mu \mathrm{m}$.

synaptobrevin I-IR was present in large axons, whereas synaptobrevin II-IR was localized in thin and medium-sized axons in sciatic nerve and dorsal root (data not shown).

In the peripheral terminals of the muscles, synaptobrevin I-IR was strong in motor endplates (Fig. 6A), whereas synaptobrevin II-IR was very low. Synaptobrevin I- and II-IR were, however, colocalized in muscle spindles (Fig. 6B) and to some extent in perivascular terminals (Fig. $6 \mathrm{C}$ ), the latter clearly containing more synaptobrevin II-IR than synaptobrevin I-IR.

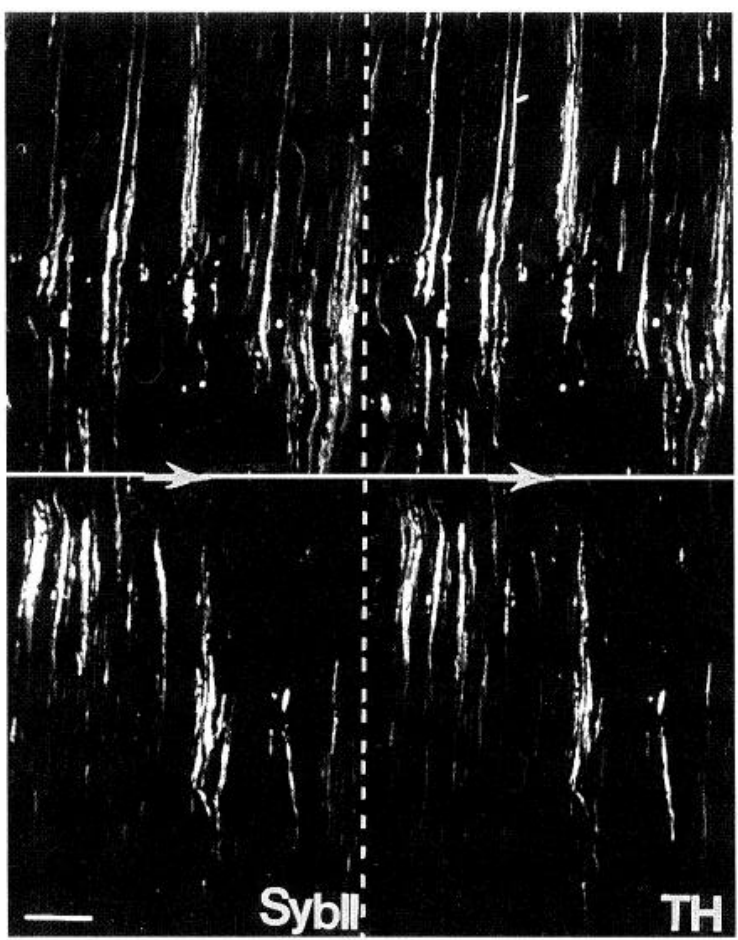

Figure 7. CLSM photomicrographs of sciatic nerve $6 \mathrm{hr}$ after crush operation. The sections were double-incubated with anti-synaptobrevin II (left lane) and anti-TH (right lane). The dotted lines mark the border between the two channels. Arrows indicate the site of the crush, proximal orientation is to the top of the figures. All TH-positive axons were positive also for synaptobrevin II, proximal as well as distal to the crush. Scale bar, $100 \mu \mathrm{m}$.

To study the origin of synaptobrevin I- and II-positive axons in the sciatic nerve, lumbar sympathectomy and ventral rhizotomy were performed by means of surgical removal of the sympathetic adrenergic or motor input to the sciatic nerve, respectively. Three days after ventral rhizotomy, the number of synaptobrevin I-positive axons was drastically reduced, whereas no clear alteration of synaptobrevin II-IR axons was observed. In contrast, after lumbar sympathectomy the number of synaptobrevin II-positive axons in the sciatic nerve was markedly decreased, whereas no obvious change in number of synaptobrevin I-positive axons was noted (data not shown).

To characterize synaptobrevin-containing neurons further, we performed double-labeling experiments with anti-TH and anti-SP. $\mathrm{TH}$, a key enzyme in catecholamine synthesis, was used as a convenient adrenergic marker to identify sympathetic neurons (Goldstein et al., 1972). As shown in Figure 7, all TH-positive axons also were positive for synaptobrevin II, confirming that synaptobrevin II was present in sympathetic adrenergic neurons. In addition, double labeling with anti-SP, a sensory marker (Hökfelt et al., 1977), revealed that SP-IR and synaptobrevin II-IR also were largely colocalized in sensory neurons in both the sciatic nerve and the dorsal roots (Fig. $8 E$ ). In contrast, in the spinal cord, only partial colocalization was observed in the ventral (Fig. $8 A$, arrows) and dorsal horns (laminae I-II) (Fig. 8B, arrows). Many terminals only displayed either synaptobrevin II-IR or SP-IR (Fig. 8A,B, arrowheads). In DRG, substance P-positive neurons also were synaptobrevin II-immunoreactive (Fig. $8 C$, arrows). Some synaptobrevin II-positive perivascular terminals also were positive for SP (Fig. $8 D$ ). High-magnification analysis showed that synaptobrevin II-IR was present in a fine granular 

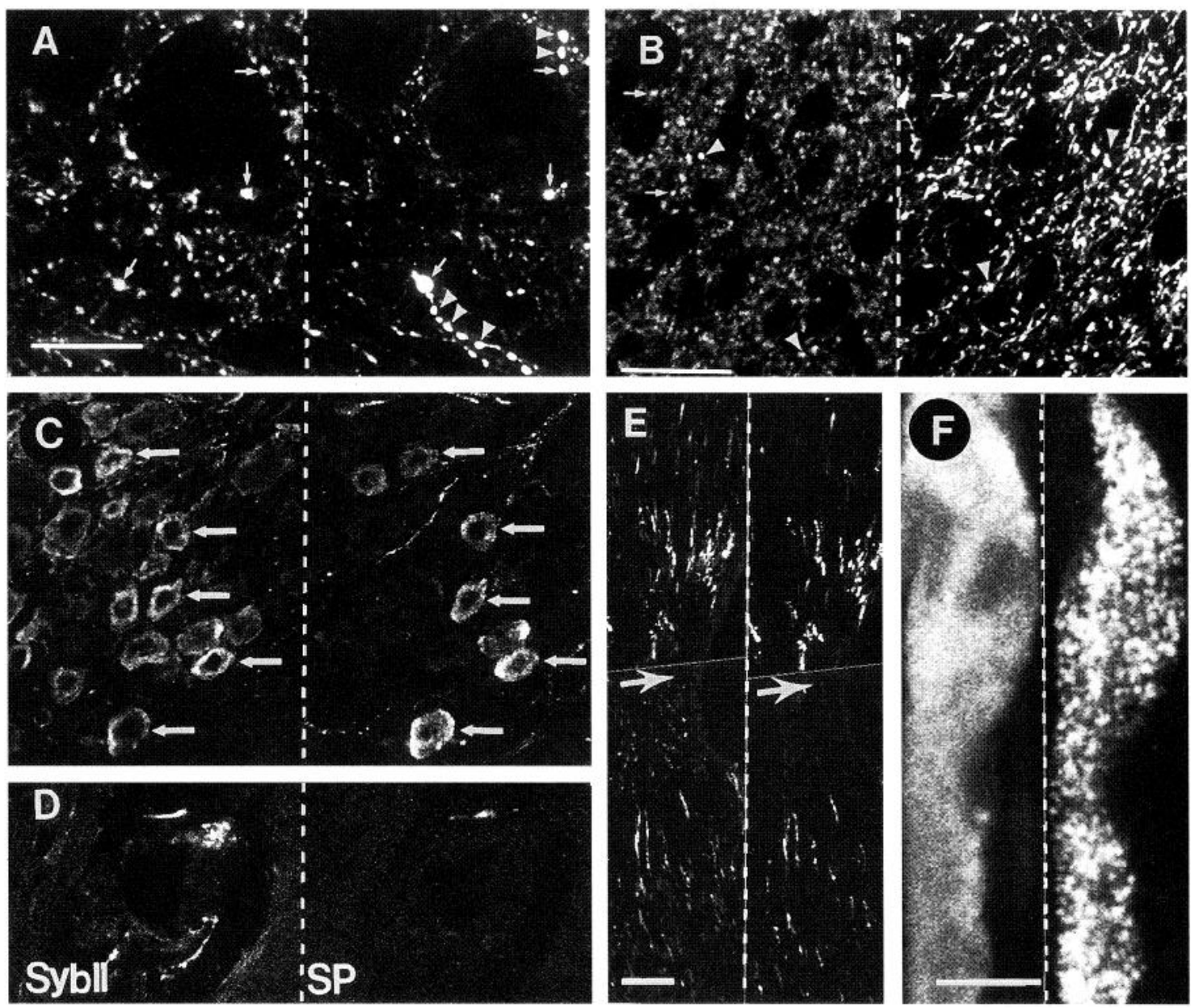

Figure 8. CLSM photomicrographs of spinal cord $(A$ and $B)$, DRG $(C)$, muscle $(D)$, and dorsal root $(E$ and $F) 6 \mathrm{hr}$ after crush operation. The sections were double-incubated with anti-synaptobrevin II (left lane) and anti-SP (right lane). The dotted lines indicate the border between the two channels. Synaptobrevin II-IR is present in many terminals in the ventral horn $(A)$. In the dorsal horn the number of synaptobrevin II-positive terminals was higher $(B)$. Only partial colocalization with SP-IR is observed (arrows), and many terminals are only positive for either synaptobrevin II or SP (arrowheads). $C$, All SP-positive DRG neurons are also positive for synaptobrevin II (arrows). D, Few synaptobrevin II-positive perivascular terminals are also SP-positive. $E$, Arrows indicate the site of the crush of the dorsal root; proximal orientation is toward the top. Synaptobrevin II-IR and SP-IRs are essentially colocalized in all the axons. $F$, Synaptobrevin II-IR appears in fine granules, whereas SP-IR is distributed in large granules. Scale bars: $50 \mu \mathrm{m}$ in $A$ and $B ; 100 \mu \mathrm{m}$ in $C-E ; 5 \mu \mathrm{m}$ in $F$.

pattern, whereas SP-IR appeared in large granules (Fig. $8 F$ ), indicating a difference in the subcellular distribution of synaptobrevin II and SP.

\section{Electron microscopic localization of synaptobrevin I and II in axons and peripheral nerve terminals}

To determine the subcellular localization of synaptobrevin I and II during axonal transport and in nerve terminals of spinal cord, we performed immunogold labeling of broken cell preparations after embedding in agarose (see Materials and Methods for details). In nerve terminals of spinal cord, labeling for synaptobrevin I was found to be concentrated around small synaptic vesicles (Fig. 9A,B). No labeling of other structures, including the presynaptic membrane, was observed. A very similar picture was obtained when nerve terminals were labeled for synaptobrevin II (Fig. 10A). Again, labeling was observed predominantly around small synaptic vesicles. In addition, some labeling also was observed around a structure reminiscent of large dense-core vesicles (Fig. 10A, arrows). These data confirm that in the spinal cord both synaptobrevins are associated predominantly with the membrane of synaptic vesicles. We then studied the morphology of synapto- brevin-positive organelles in the sciatic nerve after ligation, using both proximal and distal segments for analysis to differentiate between anterogradely and retrogradely transported organelles. In the proximal segment, dense labeling for both synaptobrevin I and II was found around small vesicular profiles with a morphology similar to that of mature synaptic vesicles (Figs. 9C,D, 10B). Again, nonspecific labeling was minimal as demonstrated by the absence of labeling on mitochondrial membranes (Fig. 9C,D). These observations suggest that synaptobrevin is associated with the synaptic vesicles (or their precursors) during anterograde axonal transport. In the distal segments, labeling for both synaptobrevin I and II was found on a more heterogeneous clear vesicle population including some large membrane profiles (Figs. 9E, $10 C)$.

\section{DISCUSSION}

In the present study, we have investigated the axonal transport of synaptobrevin I and II, two closely homologous neuronal proteins that play an essential role in exocytosis of synaptic vesicles (Söllner et al., 1993a,b) (for review, see Rothman and Warren, 1994; 


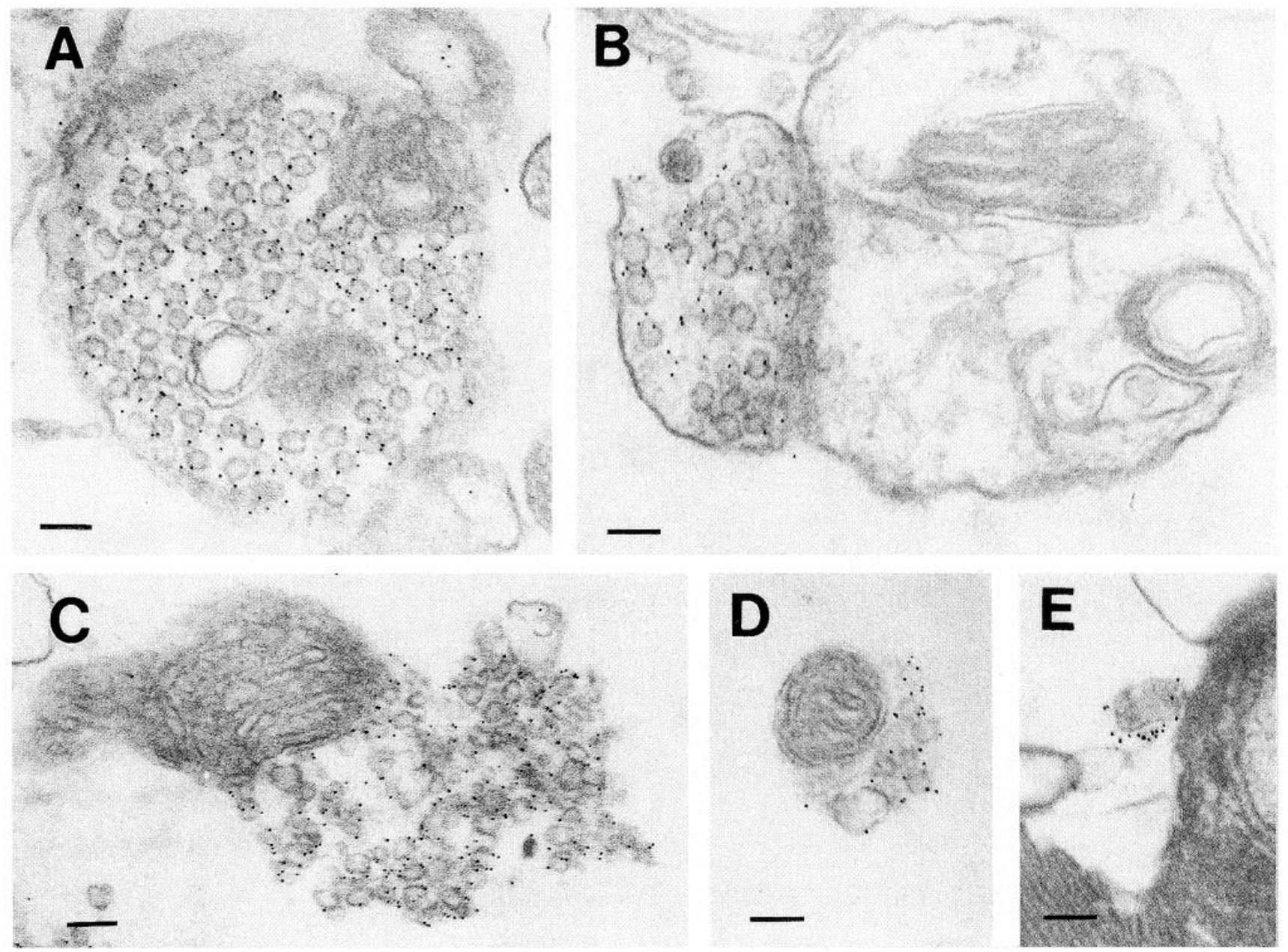

Figure 9. Agarose-embedded immunogold labeling of synaptobrevin I in spinal cord $(A$ and $B)$ and sciatic nerve 6 hr after crush operation, proximal $(C$ and $D)$ and distal $(E)$ to the crush. Synaptobrevin $I$ is associated with synaptic vesicles in nerve terminals $(A$ and $B)$ and also with the vesicles transported from the cell body to terminals $(C$ and $D)$. Dense labeling also can be seen around an organelle in retrograde transport $(E)$. Scale bars, $100 \mathrm{~nm}$.

Ferro-Novick and Jahn, 1994). In addition, we have studied the distribution of both proteins in the spinal cord and in the peripheral nervous system.

Nerve terminals lack the biosynthetic machinery to make proteins; therefore, all the synaptic vesicle-associated proteins are synthesized in the cell body and exported to the nerve terminals by means of anterograde axonal transport. However, little is known about how these proteins are associated with other proteins or organelles during the transport, and to what extent the proteins are recycled to the cell body after the end of their functional life span in the terminal. Our data demonstrate that both isoforms of synaptobrevin are transported by fast axonal transport, both anterogradely and retrogradely. As with other integral membrane proteins of the synaptic vesicle, the percentage of retrogradely transported protein was quite high ( 47 and $62 \%$ for synaptobrevin I and II, respectively). Thus, it appears that although synaptic vesicle constituents are partially degraded during their lifetime in the distal part of the axon, a major portion returns to the neuronal cell body for further processing and/or degradation. Interestingly, nonintegral membrane constituents of synaptic vesicles such as synapsin I (Bööj et al., 1986; Dahlström et al., 1992) or rab3A (Dahlström and $\mathrm{Li}, 1994$; $\mathrm{Li}$ et al., 1995) return to a far lower degree. In particular, rab3A is virtually absent from retrogradely accumulating material ( $\mathrm{Li}$ et al., 1995), making this protein a specific marker for anterogradely transported precursors of synaptic vesicles.

Electron microscopic analysis revealed that anterogradely transported synaptobrevins are highly concentrated on the membrane of small vesicular profiles that are reminiscent of synaptic vesicles. This is in agreement with previous observations that synaptic vesicle-like profiles accumulate on the proximal side of a ligation ( $\mathrm{Li}$ et al., 1995) and indicates that synaptic vesicle precursors within the axon are morphologically indistinguishable from mature synaptic vesicles. In neuroendocrine cells, it has been demonstrated that synaptic vesicle precursors are first targeted to a constitutive round of recycling before they are regenerated from early endosomes and targeted to the regulated membrane pool (Regnier-Vigouroux et al., 1991). It remains to be established whether a similar route also is followed in fully differentiated neurons. The striking similarity of the transported organelles with mature synaptic vesicles may suggest that these vesicles are already fully differentiated and are targeted directly to the regulated pool in the nerve terminal. Further studies are required to resolve this issue. 

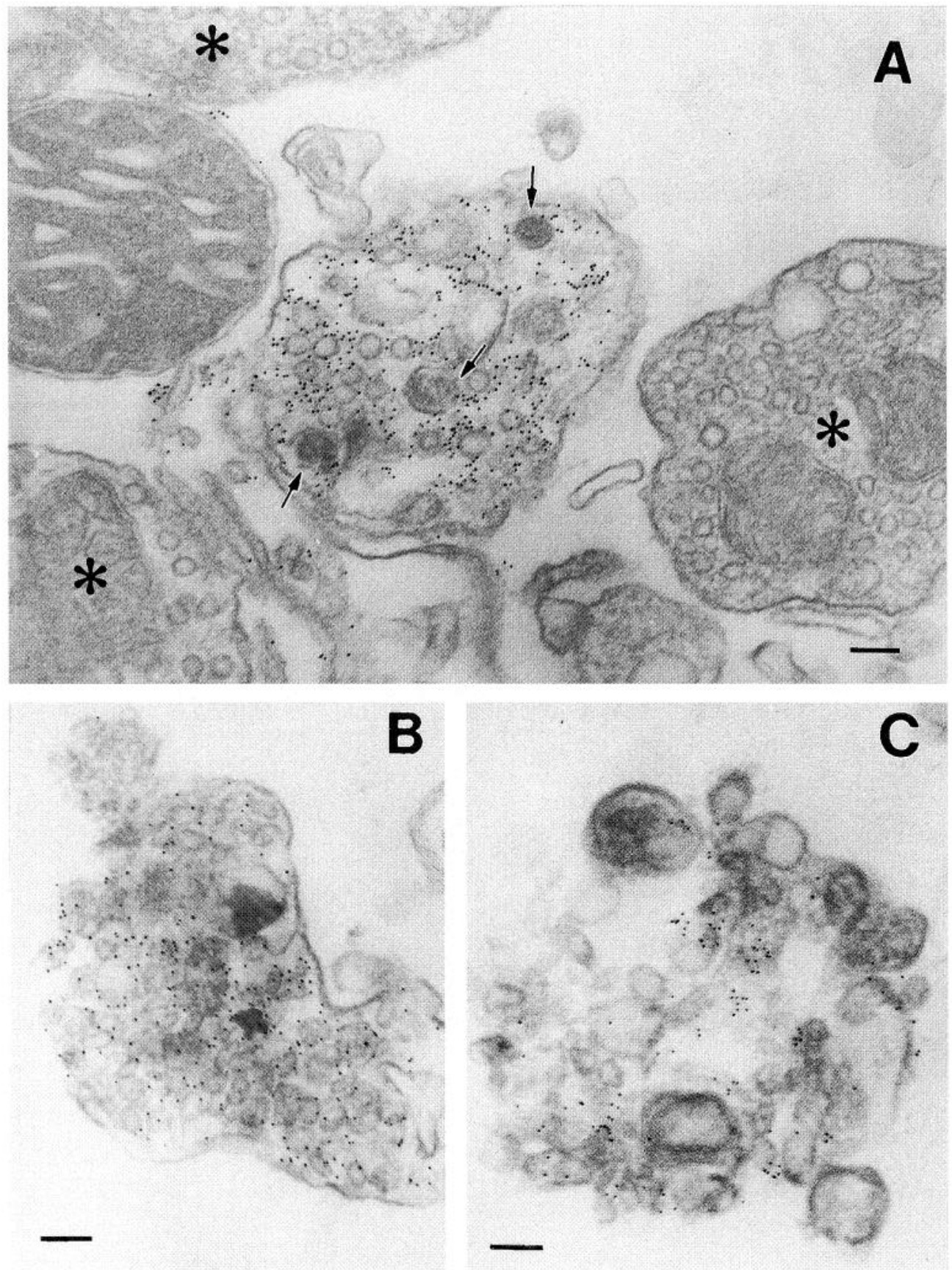

Figure 10. Agarose-embedded immunogold labeling of synaptobrevin II in spinal cord $(A)$ and of sciatic nerve $6 \mathrm{hr}$ after crush operation proximal $(B)$ and distal (C) to the crush. A, Synaptobrevin II is concentrated heavily around small synaptic vesicles in a nerve terminal. The large dense-core vesicles also appear to be labeled (arrows). The vesicles in three synaptic compartments are devoid of labeling (asterisks). B, Synaptobrevin II is associated with vesicles in sciatic nerve proximal to the crush. $C$, Synaptobrevin II is selectively affiliated with some large membrane profiles recycling to the cell body. Scale bars, $100 \mathrm{~nm}$.
Interestingly, the morphology of the retrogradely transported organelles was different. Frequently, larger membrane cisternae were observed that were not seen on the proximal side. These structures are similar to those observed by Janetzko et al. (1989) which carried the synaptic vesicle protein SV2. This agrees with the notion that retrograde transport involves early and/or late endosomal compartmentation which in non-neuronal cells have been demonstrated to have a similar morphology (Griffith and Gruenberg, 1991).

Most synaptic vesicle proteins, including the synaptobrevins, consist of multiple isoforms, but the functional significance of different isoforms is not known. As a basis for further functional studies, we have analyzed the distribution of both synaptobrevin isoforms in the peripheral nervous system, where an identification of neuronal pathways often is easier than in the CNS. Our results show that, although there is some overlap in the distribution of both proteins, they display a highly specific and differential distribution. Synaptobrevin I is expressed predominantly in large axons of the sciatic nerve, which probably represent efferent motoneurons in the spinal roots and in motor endplates. In contrast, synaptobrevin II is present mainly in thin and medium-sized axons and perivascular terminals, whereas no or very little synaptobrevin II could be detected in large axons and motor endplates. Ventral rhizotomy, lumbar sympathectomy, as well as the double-labeling experiments with anti-synaptobrevin II and anti-TH, a sympathetic adrenergic marker, or anti-SP, a sensory marker, confirmed that synaptobrevin I was present predominantly in motor neurons, whereas synaptobrevin II was abundant in sympathetic adrenergic and sensory neurons.

The significance of this highly specific expression pattern is not clear. However, Fykse et al. (1993), who demonstrated a differ- 
ential distribution of synaptophysin I and II in the nervous system, presented two alternative hypotheses for the functional meaning of multiple isoforms. One was that isoforms of synaptic vesicle proteins may be isofunctional and expressed in alternative neuronal pathways. The other was that synaptic vesicle protein isoforms may contain functional specializations that distinguish them from each other. Concerning the differences in structural, morphological, and physiological characteristics among motor, sensory, and sympathetic adrenergic neurons, each type of neuron possesses its own specific nature. The motor neurons, insensitive to NGF, form classical synapses (presynaptic, postsynaptic compartments, and synaptic cleft), and the release of vesicle contents is triggered by the influx of $\mathrm{Ca}^{2+}$, which occurs when voltage-gated $\mathrm{Ca}^{2+}$ channels in the terminals are opened in response to depolarization of the terminals by an action potential. However, the NFG-sensitive adrenergic and sensory neurons rarely make "close" synaptic contacts with their effector tissues (vessels, or smooth muscles, etc.). The neurotransmitter release from adrenergic terminals is intermittent (for review, see Brock and Cunnane, 1993). It is not clear whether real neurotransmitter release occurs regularly in the sensory terminals; however as a result of axon reflexes, SP has been reported to be released from these terminals (Brodin et al., 1981). Our data suggest that different isoforms are involved in different release mechanisms.

In the adult rat peripheral nervous system, synaptobrevin I was present predominantly in the motor system, whereas synaptobrevin II, in contrast, appeared in sympathetic adrenergic and sensory neurons. At the light microscopic level, synaptobrevin II-IR showed a distribution similar to SP-IR in axons of the sciatic nerve and the dorsal root (Fig. $8 F$ ). However, the finely granular staining pattern of synaptobrevin II differs from the coarse granular pattern of SP, suggesting that the subcellular distribution of the two proteins may be different. This is not surprising because the neuropeptide SP is confined to large dense-core vesicles, whereas synaptobrevins are abundant residents of small clear vesicles. However, our electron microscopic data demonstrate that some labeling of large dense-core vesicles is obtained with antibodies for synaptobrevin II. This suggests that synaptobrevins are probably present not only on small clear vesicles but also on large dense-core vesicles, in contrast to previous observations (Baumert et al., 1989). This agrees well with the observation that botulinal neurotoxins specific for synaptobrevin block the release of both classical transmitters and neuropeptides (McMahon et al., 1992). It is possible that the concentration of synaptobrevin is lower on large dense-core than on small clear vesicles. Further investigation using double immuno-electron microscopy, for example, is necessary to elucidate these questions.

\section{REFERENCES}

Baldini G, Hohl T, Lin HY, Lodish HF (1992) Cloning of a Rab3 isotype predominantly expressed in adipocytes. Proc Natl Acad Sci USA 89:5049-5052.

Baumert M, Maycox PR, Navone F, De Camilli P, Jahn R (1989) Synaptobrevin: an integral membrane protein of 18,000 daltons present in small synaptic vesicles of rat brain. EMBO J 8:379-384.

Bennett MK, Scheller RH (1994) A molecular description of synaptic vesicle membrane trafficking. Annu Rev Biochem 63:63-100.

Bööj S, Goldstein M, Fischer-Colbrie R, Dahlström A (1989) Calcitonin gene-related peptide and chromogranin A: presence and intraaxonal transport in lumbar motor neurons in the rat, a comparison with synaptic vesicle antigens in immunohistochemical studies. Neuroscience 30:479-501.

Bööj S, I arsson P-A, Dahllöf A-G, Dahlström A (1986) Axnnal transport of synapsin I- and cholinergic synaptic vesicle-like material; further immunohistochemical evidence for transport of axonal cholinergic transmitter vesicles in motor neurons. Acta Physiol Scand 128:155-165.

Bradford MM (1976) A rapid and sensitive method for the quantitation of microgram quantities of protein utilizing the principle of protein-dye binding. Anal Biochem 72:248-254.

Brock JM, Cunnane TC (1993) Neurotransmitter release mechanisms at the sympathetic neuroeffector junction. Exp Physiol 78:591-614.

Brodin E, Gazelius B, Lundberg JM, Olgart L (1981) Substance P in trigeminal nerve endings: occurrence and release. Acta Physiol Scand 111:501-503.

Calakos N, Bennett MK, Peterson KE, Scheller RH (1994) Proteinprotein interactions contributing to the specificity of intracellular vesicular trafficking. Science 263:1146-1149.

Calakos N, Scheller RH (1994) Vesicle-associated membrane protein and synaptophysin are associated on the synaptic vesicle. J Biol Chem 269:24534-24537.

Dahlström A, Czernik AJ, Li J-Y (1992) Organelles in fast axonal transport - what molecules do they carry in anterograde versus retrograde directions, as observed in mammalian systems? Mol Neurobiol 6:157-177.

Dahlström A, Larsson P-A, Carlson SS, Bööj S (1985) Localization and axonal transport of immunoreactive cholinergic organelles in rat motor neurons-an immunofluorescent study. Neuroscience 14:607-625.

Dahlström A, Li J-Y (1994) Fast and slow axonal transport-different methodological approaches give complementary information: contributions of the stop-flow/crush approach. Neurochem Res 19:1413-1419.

Dahlström A, Kling-Peterson A, Bööj S, Lundmark K, Larsson P-A (1989) Quantification of axonally transported material using cytofluorimetric scanning. J Microscopy 103:308 -319 .

Damer CK, Creutz CE (1994) Secretory and synaptic vesicle membrane proteins and their possible roles in regulated exocytosis. Neuroscience 43:511-536.

De Camilli P, Harris SM, Huttner WB, Greengard P (1983) Synapsin I (Protein I), a nerve terminal-specific phosphoprotein. II. Its specific association with synaptic vesicles demonstrated by immunocytochemistry in agarose-embedded synaptosomes. J Cell Biol 96:1355-1373.

Edelmann L, Hanson PI, Chapman ER, Jahn R (1995) Synaptobrevin binding to synaptophysin: a potential mechanism for controlling the exocytotic fusion machine. EMBO J 14:224-231.

Elferink LA, Trimble WS, Scheller RH (1989) Two vesicle-associated membrane protein genes are differentially expressed in the rat central nervous system. J Cell Biol 19:11061-11064.

Ferro-Novick S, Jahn R (1994) Vesicle fusion from yeast to man. Nature 370:191-193.

Fykse EM, Takei K, Walch-Solimena C, Geppert M, Jahn R, De Camilli P, Südhof TC (1993) Relative properties and localizations of synaptic vesicle protein isoforms: the case of the synaptophysins. J Neurosci 13:4997-5007.

Geppert M, Archer BT, Südhof TC (1991) Synaptotagmin II: a novel differentially distributed form of synaptotagmin I. J Biol Chem 266:13548-13552.

Goldstein M, Fuxe K, Hökfelt T (1972) Characterization and tissue localization of catecholamine synthesizing enzymes. Pharmacol Rev 24:298-309.

Griffiths G, Gruenberg J (1991) The arguments for pre-existing early and late endosomes. Trends Cell Biol 1:5-9.

Hökfelt T, Johansson O, Kellerth J-O, Ljungdahl $\AA$, Nilsson G, Nygårds A, Pernow B (1977) Immunohistochemical distribution of substance P. In: Substance P (Von Euler US, Pernow B, eds), pp 117-145. New York: Raven.

Jahn R, Südhof TC (1993) Synaptic vesicle traffic: rush hour in the nerve terminal. J Neurochem 61:12-21.

Jahn R, Südhof TC (1994) Synaptic vesicles and exocytosis. Annu Rev Neurosci 17:219-246.

Janetzko A, Zimmermann H, Volknandt W (1989) Intraneuronal distribution of a synaptic vesicle membrane protein: antibody binding sites at axonal membrane compartments and trans-Golgi network and accumulation at nodes of Ranvier. Neuroscience 32:65-77.

Laemmli UK (1970) Cleavage of structural proteins during the assembly of the head of bacteriophage T4. Nature 227:680-685.

Larsson P-A (1985) Axonal transport of amine storage granules in sympathetic adrenergic neurons: a biochemical and cytofluorimetric scanning study. PhD thesis, ISBS 91-7222-930-6, Justnu-Tryck Varberg, Göteborg. 
Li J-Y, Jahn R, Dahlström AB (1994) Synaptotagmin I is present mainly in autonomic and sensory neurons of the rat peripheral nervous system. Neuroscience 63:837-850.

Li J-Y, Jahn R, Dahlström AB (1995) Rab3a, a small GTP-binding protein, undergoes fast anterograde transport but not retrograde transport in neurons. Europ J Cell Biol 67:297-307.

Li J-Y, Kling-Peterson A, Dahlström AB (1992) Influence of spinal cord transection on the presence and axonal transport of CGRP-, chromogranin A-, VIP-, synapsin I- and synaptophysin-like immunoreactivities in rat motor nerve. J Neurobiol 23:1094-1110.

Link E, Edelmann L, Chou JH, Binz T, Yamasaki S, Eisel U, Baumert M, Südhof TC, Niemann H, Jahn R (1992) Tetanus toxin action: inhibition of neurotransmitter release linked to synaptobrevin proteolysis. Biochem Biophys Res Commun 189:1017-1023.

McMahon HT, Foran P, Dolly JO, Verhage M, Wiegant VM, Nicholls DG (1992) Tetanus toxin and botulinum toxins type $A$ and $B$ inhibit glutamate, $\gamma$-aminobutyric acid, aspartate, and met-enkephalin release from synaptosomes: clues to the locus of action. J Biol Chem 267:21338-21343.

Pevsner J, Hsu S-C, Braun JEA, Calakos N, Ting AE, Bennett MK, Scheller RH (1994) Specificity and regulation of a synaptic vesicle docking complex. Neuron 13:353-361.

Régnier-Vigouroux A, Tooze SA, Huttner WB (1991) Newly synthesized synaptophysin is transported to synaptic-like microvesicles via constitutive secretory vesicles and the plasma membrane. FMBO J 10:3589-3601.

Rothman JE, Warren G (1994) Implications of the SNARE hypothesis for intracellular membrane topology and dynamics. Curr Biol 4:220-223.

Schiavo G, Benfenati F, Poulain B, Rossetto O, Polverino de Laureto P, DasGupta BR, Mantecucco C (1992) Tetanus and botulinum-B neurotoxins block neurotransmitter release by proteolytic cleavage of synaptobrevin. Nature 359:832-835.

Söllner T, Bennett MK, Whiteheart SW, Scheller RH, Rothman JE (1993a) A protein assembly-disassembly pathway in vitro that may correspond to sequential steps of synaptic vesicle docking, activation, and fusion. Cell 75:409-418.

Söllner T, Whiteheart SW, Brunner M, Erdjument-Bromage H, Geromanos S, Tempst P, Rothman JE (1993b) SNAP receptors implicated in vesicle targeting and fusion. Nature 362:318-324.

Südhof TC, Baumert M, Perin MS, Jahn R (1989a) A synaptic vesicle membrane protein is conserved from mammals to Drosophila. Neuron 2:1475-1481.

Südhof T, Czernik AJ, Kao H-T, Takei K, Johnston PA, Horiuchi A, Kanazir SD, Wagner MA, Perin MS, Greengard P (1989b) Synapsins: mosaics of shared and individual domains in a family of synaptic vesicle phosphoproteins. Science 245:1474-1480.

Towbin H, Staehelin T, Gordon J (1979) Electrophoretic transfer of proteins from polyacrylamide gels to nitrocellulose sheets: procedure and some applications. Proc Natl Acad Sci USA 76:4350-4354.

Trimble WS, Gray TS, Elferink LA, Wilson MC, Scheller RH (1990) Distinct patterns of expression of two VAMP genes within the rat brain. J Neurosci 10:1380-1387.

Yamasaki S, Baumeister A, Binz T, Blasi J, Link E, Cornille F, Roquest B, Fykse EM, Südhof TC, Jahn R, Niemann H (1994a) Cleavage of members of the synaptobrevin/VAMP family by types $\mathrm{D}$ and $\mathrm{F}$ botulinal neurotoxins and tetanus toxin. J Biol Chem 269:12764-12772.

Yamasaki S, Binz T, Hayashi T, Szabo E, Yamasaki N, Eklund M, Jahn R, Niemann $H(1994 b)$ Botulinum neurotoxin type $G$ proteolyses the Ala81-Ala82 bond of rat synaptobrevin 2. Biochem Biophys Res Commun 200:829-835.

Yamasaki S, Hu Y, Binz T, Kalkuhl A, Kurazono H, Tamura T, Jahn R, Kandel E, Niemann H (1994c) Synaptobrevin/vesicle-associated membrane protein (VAMP) of Aplysia californica: structure and proteolysis by tetanus toxin and botulinal neurotoxin type D and F. Proc Natl Acad Sci USA 91:4688-4692. 